\title{
La poesía de Xavier Villaurrutia
}

Con la muerte de Xavier Villaurrutia, perdió México uno de sus más destacados valores poéticos. Poeta de la soledad y de la angustia, aunque poco o nada existencialista, logró recrear en sus versos el sentimiento de horror ante la vida, que es una de las características del hombre contemporáneo.

Sus escasa producción poética abarca sólo tres volúmenes pequeños y unos poemas no coleccionados. Esto se debe a las necesidades interiores del poeta mismo; creía firmemente en la naturaleza intelectual de la poesía, y para él, escribir quería decir pensar $\mathrm{y}$ volver a pensar, hasta el momento en que "... no tengo ningún mandato y puedo decirme: ‘Ahora sé que voy a escribir! Es decir, escribo inevitablemente, i esa es la palabra exacta!" 1

Reflejos, su primer volumen, apareció en 1927. Forma parte del movimiento, llámese poesía pura o como quiera, que trató de crear un retrato objetivo del mundo sin que el poeta se mezclara en su poema. Reflejos son: de la atmósfera, de un jardín, de la vida que rodea al poeta.

Lo mejor del volumen es el grupo de poesias llamado "Suite del Insomnio", donde el "Eco"

... juega con los ruidos

copiándolos en sus espejos

de sonidos.

El lejano sonido del tren se persigue a sí mismo por la noche, y "Tranvías" son

Casas que corren locas

de incendio, huyendo

de sí mismas... 
Pero dentro de la objetividad de estos Reflejos, hay una nota de melancolía. En "Sueño" se pregunta el poeta si los amantes estarán juntos en la vida como en el sueño. Esta melancolía se torna ennui increíble: el mundo visto desde la loma es un "puzzle" que no vale la pena de arreglar. Crece la melancolía mientras se aguza dentro del poeta su sentimiento de la soledad que lo sigue desde los ojos del retrato ("Soledad"). Quiere huir

para que el domingo fuera detrás del tren persiguiéndome...

("Domingo".)

Quiere huir del silencio que

... nos ha estrujado, inútiles, en los rincones.

("Fonógrafos".)

Y crece la soledad.
La soledad se agranda
como las sombras
en la sábana del muro, como las caras de ayer...
("Amplificaciones".)

Ya se desvía Villaurrutia de la objetividad para irse camino del solipsismo que es uno de los grandes temas de Nostalgia de la Muer$t e$, cumbre de su poesía, aparecida en forma definitiva en 1946.

En Nostalgia de la Muerte, la melancolía se ha hecho angustia y la soledad es amenaza. Es este libro una afirmación de las realidades filosóficas que persiguen al poeta en la lucidez desesperada de la noche. Veamos estos asertos en algunos de los poemas recogidos en dicho volumen, especialmente los "Nocturnos".

En "Nocturno miedo" Villaurrutia recuerda los pensamientos que lo atacan en sus andanzas nocturnas. Todo es duda; en el misterio de la noche se han perdido el individuo y la personalidad. E1 hombre resulta ser intelecto sin cuerpo:

¿Y quién entre las sombras de una calle desierta, en el muro, lívido espejo de soledad, 
no se ha visto pasar o venir a su encuentro y no ha sentido miedo, angustia, duda mortal?

El miedo de no ser sino un cuerpo vacío que alguien, yo mismo o cualquier otro, puede ocupar y la angustia de verse fuera de sí, viviendo, y la duda de ser o no ser realidad.

Hundido en su solipsismo, incapaz de encontrar a otro que le diga, "Te veo. Existes", el poeta ni está seguro de que le pertenezca el mismo cuerpo. Está rodeado de espejos (muros, personas) que le devuelven siempre el mismo reflejo, el único, el suyo.

Quizá el más poderoso de estos "Nocturnos" es el "Nocturno de la estatua". Sueña con una estatua que le huye gritando. El poeta la persigue, pero sólo halla el grito; cuando trata de asirlo, encuentra sólo el eco. Quiere prender el eco y toca un muro, que a su vez se vuelve espejo opaco en el que el poeta no ve más que a sí mismo. Esta progresión simboliza la búsqueda, el intento de hallar a otro en la zona de soledad completa a la que lo ha conducido la razón. Desaparece todo lo que afronta, y halla el compañero único y eterno: él mismo. Cuando, al final, descubre a la estatua asesinada, y le da vida en un "... cerrar de ojos...", puesto que sólo en sueños encuentra to que busca, ella le dice, "... estoy muerta de sueño." Hasta la compañera de sueños se muere de la enfermedad fatal, que no es más que una ", .. cotidiana muerte provisional." 2

Asediado por este concepto filosófico, al mismo tiempo sumamente personal, Villaurrutia nunca pudo refugiarse en él. Ni en la vigilia ni en el sueño, ni en ese momento atemporal antes de dormirse, momento que no es ni sueño ni vigilia, pudo su intelecto hallar descanso. En "Nocturno en que nada se oye", la inteligencia pura anota sus pensamientos en ese momento en que la conciencia ha salido del cuerpo, esa "... estatua sin sangre...", para bajar en un viaje sin fin, por el agua que no moja, por el aire que parece de vidrio, por la llama lívida: símbolos del movimiento de la mente por ese reinado donde todo es 10 mismo, y a la vez tan distinto que da miedo.

En este poema vemos una técnica del autor que se ha comprendido mal. Frecuentemente se le tacha de jugar con palabras. Los 
versos que más han provocado esta mala interpretación son los siguientes:

$$
\begin{aligned}
& \text {.. y mi voz que madura } \\
& \text { y mi voz quemadura } \\
& \text { y mi bosque madura } \\
& \text { y mi voz quema dura... }
\end{aligned}
$$

Estos versos han sido aclarados magistralmente por José Luis Martínez. ${ }^{3}$ Se remonta a un verso anterior.

$\mathrm{Y}$ en el juego angustioso de un espejo frente a otro cae mi voz...

Dice Martínez, “... es... un medio gráfico y sutil para representar el rebote angustioso de una voz caída entre el mutuo e infinito reflejo de un espejo frente a otro, reproducido una vez y otra vez, en su superficie, en diferentes matices representados por el juego de las palabras que conservan idénticos fonemas." Aquí queremos subrayar to que creemos el verdadero significado de los versos, el intento de reproducir la ilusión de oír la propia yoz como suena y vuelve a sonar precisamente en el momento en que se pierde la conciencia. Fenómeno muy conocido por los que han sido anestesiados.

Un poco más tarde se repite la técnica:

$$
\begin{aligned}
& \text {... aquí en el caracol de la oreja } \\
& \text { el latido de un mar en el que no sé nada } \\
& \text { en el que no se nada... }
\end{aligned}
$$

Oye el poeta el pulso de la sangre, y lo interpreta como el latir de un mar del cual no sabe nada, porque se produce en el momento de dormirse. Un mar en el que no se nada, porque es un mar fatal que volverá a oírse cuando cambiemos esta "... cotidiana muerte provisional..." por el final y único aniquilamiento del ser. Nada se oye, en ambos sentidos: todo está en silencio, pero la Nada habla claro.

En "Nocturno en que habla la Muerte" hace patente el poeta el segundo de sus temas: la muerte inminente. Piensa Villaurrutia en la posibilidad de que $s u$ muerte particular lo haya acompañado, no mental ni espiritualmente, sino 
... escondida en un hueco de mi ropa en la maleta, en el bolsillo de uno de mis trajes,

entre las páginas de un libro...

La Muerte ya no es entidad abstracta; se ha hecho compañera. Escuchamos las palabras de ella, tales como las imagina el poeta. Están entre lo mejor de la poesía de Villaurrutia. Habla, sencilla y directamente:

... Aquí estoy.

Te he seguido como la sombra

que no es posible dejar así nomás en casa;

como un poco de aire cálido e invisible

mezclado al aire duro y frío que respiras;

como el recuerdo de lo que más quieres...

La Muerte, con mayúscula, ya es casi la amada, "... lo que más quieres..." Y el poeta tiene la confianza angustiosa de que no está a solas:

$\mathrm{Y}$ al oprimir la pluma, algo como la sangre late y circula en ella, y siento que las letras desiguales que escribo ahora, más pequeñas, más trémulas, más débiles, ya no son de mi mano solamente.

Este concepto de la Muerte particular lo llevó Villaurrutia a su definición casi clásica, en el más acabado logro del poeta: "Décima Muerte". Es, en su forma, pariente cercano del poema amoroso renacentista, del sonnet sequence de los isabelinos. ${ }^{4}$ Pero es esto y mucho más, resumiendo todo el sufrimiento de una vida pasada en súplica y tormento. Empleando dos técnicas muty del autor, antítesis e ironía, convierte a la amada renacentista en una amada mucho más interesante $-\mathrm{y}$ de atractivos mucho más eficaces $:^{5}$

Si en todas partes estás, en el agua y en la tierra, en el aire que me encierra $y$ en el incendio voraz; y si a todas partes vas conmigo en el pensamiento, en el soplo de mi aliento 
y en mi sangre confundida, ¿no serás, Muerte, en mi vida, agua, fuego, polvo $y$ viento?

No será ninguna casualidad la semejanza entre esta "Décima Muerte" y dos de los grandes sonetos en lengua española, de dos poetas que también sabían lo que quería decir la Muerte: Góngora y Sor Juana. Es una deliberada mezcla de dos corrientes literarias, formando así una tercera y muy nueva, en la que la Muerte y la Amada son una.

Por todo el poema se halla patente este extraño amor, tan extraño que el poeta acaba por habituarse a él. En la última estrofa, subraya irónicamente el hecho de que ya la Muerte no lo puede dañar:

\author{
En vano amenazas, Muerte, \\ cerrar la boca a mi herida \\ $y$ poner fin a mi vida \\ con una palabra inerte. \\ iQué puedo pensar al verte, \\ si en mi angustia verdadera \\ tuve que violar la espera; \\ si en vista de tu tardanza \\ para llenar mi esperanza \\ no hay hora en que yo no muera!
}

Para que el lector sepa bien que esta preocupación no fué mera pose, basta decir que Villaurrutia murió de un achaque del corazón, a la edad de cuarenta y seis años, y que desde hacía tiempo sabía él muy bien que le acechaba la muerte. Esta conciencia de lo que le podía pasar en cualquier momento, lo que tenía que pasarle dentro de pocos años, le prestó una habilidad extraordinaria para expresar la agonía cerebral que sufría. Se suma esta agonía en una de sus mejores estrofas, de "Muterte en el frío":

Siento que estoy viviendo aquí mi muerte, mi sola muerte presente, mi muerte que no puedo compartir ni llorar, mi muerte de que no me consolaré jamás.

Canto a la primavera, publicado en 1948, difiere notablemente de la obra anterior del poeta. La amada ya no es la Muerte, sino 
una mujer de carne y hueso. La angustia de la muerte cercana ha sido reemplazada por la angustia sentida por el amante sin éxitos. Hay un cambio de énfasis que no logró cristalizarse; si no se hubiera interpuesto la muerte del poeta, quizá hubiera tenido desarrollo más amplio.

Esto no quiere decir que el libro sea un fracaso. Si "Amor condusse noi ad una morte" y "Soneto de la esperanza" representan un nivel poético más bajo que el de los "Nocturnos", hay que recordar que éstos están a una altura pocas veces alcanzada. Además, en los dos poemas citados y en "Nuestro amor", hay indicios de que el poeta ya iba manejando con su maestría acostumbrada esta materia nueva. "Nuestro amor" es poema amoroso, pero no es el idilio. Incluye todo momento, todo fenómeno, sea físico o mental, del amor. Este amor se basa, no en la felicidad, sino en una angustia mutua:

$$
\begin{aligned}
& \text {... si nuestro amor no fuera } \\
& \text { como un hilo tendido } \\
& \text { en que vamos los dos } \\
& \text { sin red sobre el vacío... }
\end{aligned}
$$

Por su misma naturaleza, es este amor más importante de lo que pudiera ser un anorío cualquiera; los dos están unidos como resultado de su agonía. Puede que se desvanezca la atracción, pero no este amor desesperado:

$$
\begin{aligned}
& \text {... si no fuera una larga } \\
& \text { espera interminable, } \\
& \text { un vacío en el pecho } \\
& \text { donde el corazón llama } \\
& \text { como un puño cerrado } \\
& \text { a una puerta impasible... } \\
& \text {... si no fuera un desvelo, } \\
& \text { un grito iluminado } \\
& \text { en la noche profunda... } \\
& \text {... si tus palabras fueran } \\
& \text { sólo palabras para } \\
& \text { nombrar con ellas cosas } \\
& \text { tuyas, no más, y mías; } \\
& \text { si no resucitaran, } \\
& \text { si no evocaran trágicas } \\
& \text { distancias y rencores } \\
& \text { traspuestos, olvidados... }
\end{aligned}
$$


Si su amor no fuera todo esto, si no fuera una fusión completa de su angustia mutua,

ino fuera amor el nuestro, no fuera nuestro amor!

El punto culminante de esta tercera fase de la poesía de Villaurrutia se halla en las "Décimas de nuestro amor", publicadas en Cuadernos Americanos poco después de la muerte del poeta. ${ }^{6}$ Aquí la economía de palabras, la comprensión opaca, de Nostalgia de la Muerte están aplicadas al tema nuevo. La angustia de estas "Décimas" se desprende de un fuerte choque personal que parece haber turbado mucho al poeta:

Prisionero de ti, vivo buscándote en la sombría caverna de mi agonía.

$\mathrm{Y}$ cuando a solas te invoco, en la oscura piedra toco tu impasible compañía.

Ya los muros no son espejos, pero quizá fuera mejor así, puesto que la amada es tan dura. Pero sigue buscando, en una ansia sin esperanzas:

\author{
Mi amor por ti, i no murió! \\ Sigue viviendo en la fría, \\ ignorada galeria \\ que en mi corazón cavó. \\ Por ella desciendo y no \\ encontraté la salida, \\ pues será toda mi vida \\ esta angustia de buscarte \\ a ciegas, con la escondida \\ certidumbre de no hallarte.
}

Poesía de angustia y desesperación, pocas veces igualada en la poesía mexicana. Termina el último libro de Villaurrutia en un "Epitafio" que queda, tal vez intencionadamente, como su palabra final:

Duerme aquí, silencioso e ignorado, el que en vida vivió mil y una muertes.

Nada quieras saber de mi pasado.

Despertar es morir. I No me despiertes! 
En la obra de todo artista existe el problema de las influencias. La naturaleza y el grado de influencia varía de un poeta a otro, y en el período contemporáneo el problema se torna un verdadero rompecabezas, debido a que existen patrones de interés que aparecen en la obra de poetas que no tienen ni el menor parentesco el uno con el otro. En la obra de Villaurrutia han visto muchos críticos claros indicios del rastro de Juan Ramón Jiménez. Más que crítica, esto parece ser la salida más fácil. Existen ciertas semejanzas entre la obra del gran lírico español y la nostalgia de ciertos poemas del mexicano -poemas como "Soledad" o "Cuadro", por ejemplo-; pero aun en estos poemas tempranos Villaurrutia estaba dejando atrás a este tipo de lírica. ¿ Dónde se ve a Juan Ramón en versos como "Qué dulce el agua disolviendo sales!" de "Arroyo"? Que existan ciertas semejanzas superficiales no lo podemos negar; pero se deben, creemos, más al ambiente literario en que vivía el joven poeta mexicano que a ninguna influencia verdadera. Habría sido casi imposible que no sonara algún eco de Juan Ramón en la obra de cualquier poeta joven de lengua española, como más tarde volvió a sonar tantas veces el eco de García Lorca o, en inglés, el de Eliot.

Para hallar influencias, no hay que salir de México. En la Décima Musa de México ( $\mathrm{y}$ nótese cómo, de una manera tan villaurrutiana, hay aquí un juego de palabras con "décima"), Sor Juana Inés de la Cruz, y en Ramón López Velarde, halló el joven mexicano a dos amigos quienes le ayudaron mucho a forjar su propio estilo. Lo típico de este estilo consiste en dos técnicas : 1) empleo del adjetivo o del complemento verbal, para proveer el poder de la imagen, y 2) la costumbre de emplear toda clase de juegos verbales para subrayar el significado. Encontramos que estos dos elementos desempeñan un papel importantísimo en la obra de Sor Juana y la de López Velarde.

Citemos algunos versos de "Suave Patria":

... la patria es impecable y diamantina...

... raza de bailadores de jarabe...

Cada verso se compone de dos grupos de sílabas; de siete uno, y el otro de cuatro. En cada verso es este último de cuatro sílabas, sirviendo de adjetivo o de complemento verbal, el que proporciona el 
poder poético. ". . la patria es impecable y diamantina ..." "... raza de bailadores de jarabe..." No hay manera más eficaz de describir la pureza increíble del aire del Valle de Anáhuac ni la influencia profunda de lo indio. Es esta técnica la misma que sirve de base de las mejores imágenes de Villaurrutia. Que sirva de ejemplo un verso de "Nocturno en que nada se oye":

\section{... en esta soledad $\sin$ paredes...}

E1 poder poético se encuentra precisamente en las palabras "sin paredes". Parece haber terminado el verso; súbitamente, estalla todo el horror de la soledad infinita, ilimitada. Pues bien, no es esta una técnica tan desusada que Villaurrutia no la pudiera encontrar en otras fuentes; pero siendo el mejor crítico de la poesía de López Velarde $\mathrm{y}$ habiendo editado dos volúmenes de ella, parece lógico que de él haya aprendido esta técnica. Si faltan más pruebas, queda el hecho de que Villaurrutia mismo señaló la importancia del adjetivo en la obra de López Velarde. ${ }^{7}$

En el caso de Sor Juana, la semejanza estriba en coincidencias más generales, menos detalladas. Veamos, por ejemplo, la primera estrofa de "Décima Muerte":
¿Qué prueba de la existencia habrá mayor que la suerte de estar viviendo sin verte y muriendo en tu presencia! Esta lúcida conciencia de amar a lo nunca visto y de esperar lo imprevisto; este caer sin llegar es la angustia de pensar que puesto que muero existo.

Fijémonos en la cantidad de antítesis: viviendo-muriendo; sin verteen tu presencia; muero-existo. Pues en la poesía de Sor Juana abunda esta técnica, desde el estupendo verso final del soneto "A su retrato", pasando por poemas como "Hombres necios que acusais" y "Que no me quiera Fabio, al verse amado", hasta el conceptismo neto de "Rosa divina que, en gentil cultura". Citemos los dos versos últimos de "Rosa divina...": 
¿Con que, con docta muerte y necia vida, viviendo engañas y muriendo enseñas!

La semejanza entre estos versos y los de "Décima Muerte" es innegable. Por supuesto, no podemos decir definitivamente que aquí hay un caso de influencia directa, puesto que Villaurrutia habría podido descubrir esta técnica también en la obra de cualquier poeta barroco. Sin embargo, nos parece mucho más probable que la hubiera encontrado en la obra de Sor Juana. $\mathrm{Y}$ otra vez podemos alegar: los tres volúmenes de poesías de Sor Juana editados por Villaurrutia. ${ }^{8}$

La cuestión de influencia sobre el contenido es, a lo menos en este caso, algo más difícil. Parece haber algo de Heidegger; sin embargo, queda dicho por el poeta mismo que encontrar su propia expresión poética no fué tan fácil como encontrar a Heidegger. ${ }^{9}$ Es decir, descubrió al filósofo después de formular su propio pensamiento. Además, una lectura cuidadosa de los poemas demuestra que hay diferencias entre los dos sistemas, si así podemos llamarlos. Lo que sólo parece formar parte del pensamiento de Heidegger es el tema predominante del mexicano: el hombre frente a la muerte. No negamos las semejanzas: interés por el tiempo; la importancia del concepto de angst, la angustia; el intento de comprender lo que es la muerte. Sin embargo, todo esto puede ser mera coincidencia. El tiempo es tema extendidísimo en la literatura contemporánea: Proust, Mann, Pirandello. La angustia y la muerte no pertenecen exclusivamente a Heidegger, ni mucho menos a los varios y variados grupos llamados existencialistas. Véase la poesía española barroca, como sólo un ejemplo. Además, tiene antecedentes antiguos en México, según veremos.

Otra influencia que ha sido señalada es la de Rainer María Rilke. Aquí parece haber más razón, puesto que el gran poeta alemán también desarrolló el concepto de la muerte y creó la suya particular. Los dos poetas coinciden en su actitud frente a la muerte cierta e implacable:

¿O quién podrá representar su morir siempre inminente del pan grisáceo que come endurecido?...

Pero eso: consentir la muerte, toda la muerte, aun antes de iniciar la vida, 
y con tanta dulzura retenerla, $\mathrm{y}$ aún ser noble $\mathrm{y}$ bueno, i eso es indescriptible! 10

Las palabras de Rilke pronunciadas en su lecho de muerte son amplia evidencia de la integridad que poseía. "No: déjenme morir de mi propia muerte. No quiero la muerte de los médicos." 11

Pero la poesía de Rilke demuestra claramente que en la muerte ve él lo que le abrirá la puerta a la vida por venir, vida que es el complemento necesario de los sufrimientos terrenales:

\footnotetext{
Angel: supongamos que hay un sitio del que todo ignoramos, y que ahí, en un tapete indescriptible, los amantes se mostraron todo lo que aquí nunca jamás han realizado. 12
}

De esto no hay ni el menor asomo en la poesía del mexicano. No hay ni ángeles ni porvenir, y la muerte es el fin. Afinidades, claro que las hay; pero sería difícil demostrar que había más.

Una característica de la obra de Villaurrutia es el empleo del sueño en la imagen, para demostrar lo que quiere decir. Lo hace de dos maneras: la creación de un mundo de ensueños en el que puede expresar el mundo de pesadilla en que vive, y la equivalencia del sueño y la muerte. Cuando nos dormimos, rompe los muros el mundo subconsciente del terror, y las barreras entre realidades externa e interna se derrumban. Se confunden vida y muerte, vigilia y sueño. El poeta tiene que expresar todas estas realidades complejas, y a Villaurrutia le sirvió para expresarlas el sueño.

Este es también un interés contemporáneo. Aparece en Novalis, para volver a aparecer en Nerval y Bécquer; finalmente, asume un papel importantísimo en la obra de Strindberg, Joyce, y muchísimos más. Pero Villaurrutia parece haber aprendido este doble tema-técnica de otra fuente. Dice él, “... quizá existan en mi obra, más que influençia de algunos escritores, la de un pintor. En Chirico encontré muchas veces una clara afinidad." 13 Para el que quiera entender cuán fundamental fué esta influencia, sólo hay que comparar el ambiente de cualquiera de los "Nocturnos" con las sombras amenazadoras de alguna obra de Chirico, en particular Misterio y melancolía de una calle. 
Poeta sumamente cosmopolita, fué atacado Villaurrutia por no escribir propaganda política, en vez de lo que tenía que escribir. Se le tachó de antimexicanista, afrancesado, y cosas mucho peores. A pesar de esas aseveraciones poco justas, parece haber una cantidad de pruebas que indican que fué tan mexicano el poeta como cualquiera de sus críticos, si es que así merecen ser calificados.

Existen en la obra de Villaurrutia hondas resonancias mexicanas. Recordemos que la cultura mexicana es expresión sintética de dos corrientes: la española y la india. Aquélla es la de las "Coplas" de Manrique y la poesía ácida de Quevedo, la de "La Danza de la Muerte" y los Cristos sangrientos. Esta es la de los sacrificios humanos, no a causa de ninguna sed de sangre, sino basados en la creencia de que sufrieron los dioses para crear al hombre, y por eso debe el hombre sufrir para honrar a sus dioses. "La idea del sacrificio expresa cómo la vida se nutre permanentemente de la muerte", dice Mariano Picón-Salas, y habla del "... espanto cósmico de los aztecas..." y la "... tristeza india ..." 14 En los restos de la poesía indígena de México abundan la melancolía y la preocupación de la muerte. Casi parece sacado directamente de la obra de Villaurrutia este trozo de poesía indígena. ${ }^{15}$

Nunca en verdad cesará, nunca en verdad se irá, ni se me hará soportable la tristeza que ahora expreso.

Compáresele con el verso siguiente, que es de "Muerte en el frío" de Villaurrutia:

Siento que estoy viviendo aquí mi muerte, mi sola muerte presente, mi muerte que no puedo compartir ni llorar, mi muerte de que no me consolaré jamás.

No debe extrañar que sea México la tierra de la gravedad, cuya característica nacional es la seriedad reflexiva. Existe el tema de la muerte en toda la literatura mexicana, dormida a veces, pero despertando para hacerse tema importantísimo en el siglo $\mathrm{xx}$. Existe en las artes plásticas, desde la estilización de la escultura prehispánica al horripilante mundo de la visión de Orozco, Siqueiros y Rivera. Basta la obra de los grabadores del siglo pasado, como 
testimonio del grado a que la muerte ha permeado la conciencia popular mexicana.

Como si no bastara todo esto para demostrar la mexicanidad de Xavier Villaurrutia, existe el libro interesantísimo de Octavio Paz, El laberinto de la soledad. ${ }^{16}$ Al tratar de investigar lo que es la personalidad mexicana y dónde están sus fuentes, $\mathrm{Paz}$ se ha dado cuenta de que lo que le diferencia del inglés, del francés o del argentino es el hecho de que siempre lleva consigo su muerte. Citar ejemplos sería citar el libro entero. No parece caber duda de que aquí Villaurrutia no hizo otra cosa que trabajar dentro de su propio patrón cultural.

El otro aspecto del problema, el solipsismo, se puede atribuir, al menos parcialmente, a la misma cultura. La gravedad estoica del indio y el estoicismo individualista del español forman parte de la tradición que creó al mexicano. No parece exagerado aseverar que Villaurrutia, acechado por esas corrientes y atormentado por el problema personal de la muerte -iy bien sabía lo que llevaba adentro! - hubiera creado una patria chica de su propia personalidad.

No hay por qué buscar en otras literaturas. A pesar de los que toman literatura por política, era Xavier Villaurrutia tan mexicano en la poesía como en la vida. Mexicana en cuerpo y espíritu, su obra alcanza las alturas de la universalidad, y quizá sea lo mejor de la estirpe, escrito en México hasta hoy.

\section{Frank Dauster}

\section{$\mathrm{NOT}$ A S}

1 Citado por José Luis Martínez, "Con Xavier Villaurrutia", Tierra Nueva, I, 2, (marzo-abril, 1940), 77.

2 Xavier Villaurrutia, "Seis Personajes. VI: Un joven de la Ciudad", Textos y pretextos. (México: La Casa de España en México, 1940), p. 85.

3 "Con Xavier Villaurrutia", 79.

4 Esta filiación la indica Villaurrutia mismo en el lema de Nostalgia de la Muerte. Es un verso barroquísimo del somet sequence "Idea" del inglés Michael Drayton (1563-1631). 
5 El verso último gana enormemente en intensidad, cuando el lector se da cuenta de que estos cuatro elementos son los propuestos por Empédocles como los fundamentales de la existencia.

6 Año $\mathrm{x}$, vol. 55, 1, (enero-febrero, 1951), 287-289.

7 "Ramón López Velarde. II: Su poesía", Textos y pretextos, p. 27.

8 Damos aquí los cinco volúmenes de poesías de Sor Juana y López Velarde mencionados en el texto: Sor Juana Inés de la Cruz, Endechas. Taller, vir, (dic., 1939), 59-89. Pub. como separado por Ed. Taller, 1940; —_, Sone tos, (México, 1931); - - Sonetos y Endechas, (México: Edit. Nueva Cultura, 1941); Ramón López Velarde, El León y la Virgen, (México: Edic. de la Universidad Nacional Autónoma, 1942); - Poesias escogidas, (México: Edit. Cultura, 1935; Edit. Nueva Cultura, 1940).

9 Véase la nota 3.

10 Rainer María Rilke, Elegias del Duino, (México, 1947, s. p.), tr. de Horacio Quiñones, "La Cuarta Elegía".

11 Citado por Guillermo de Torre, La aventura y el orden, (Buenos Aires: Edit. Losada, 1948), p. 151.

12 Elegías del Duino, "La quinta elegía".

13 Véase la nota 3.

14 De la Conquista a la Independencia, (México-Buenos Aires: Fondo de Cultura Económica, 1944), p. 25.

15 "Canto en loor de los Reyes". Aparece, con tanto otro ejemplo de la misma tendencia, en Poesía Indígena de la Altiplanicie, de Angel María Garibay K. (México: Universidad Nacional Autónoma, 1940).

16 México: Ediciones Cuadernos Americanos, 1947. 
